Article

\title{
Experiences with Thermal Spray Zinc Duplex Coatings on Road Bridges
}

\author{
Ole Øystein Knudsen ${ }^{1, *} \mathbb{C}$, Håkon Matre ${ }^{2}$, Cato Dørum ${ }^{2}$ and Martin Gagné ${ }^{3}$ \\ 1 SINTEF, P.O. Box 4760 Torgarden, NO-7465 Trondheim, Norway \\ 2 Norwegian Public Roads Administration, 5008 Bergen, Norway; haakon.matre@vegvesen.no (H.M.); \\ cato.dorum@vegvesen.no (C.D.) \\ 3 Zelixir Inc., Toronto, ON M5A4R4, Canada; mgagne@zelixir.ca \\ * Correspondence: ole.knudsen@sintef.no; Tel.: +47-9823-0420
}

Received: 12 May 2019; Accepted: 4 June 2019; Published: 8 June 2019

\begin{abstract}
Road bridges are typically designed with a 100-year lifetime, so protective coatings with very long durability are desired. Thermal spray zinc (TSZ) duplex coatings have proven to be very durable. The Norwegian Public Roads Administration (NPRA) has specified TSZ duplex coatings for protection of steel bridges since 1965. In this study, the performance of TSZ duplex coatings on 61 steel bridges has been analyzed. Based on corrosivity measurements on five bridges, a corrosivity category was estimated for each bridge in the study. Coating performance was evaluated from pictures taken by the NPRA during routine inspections of the bridges. The results show that very long lifetimes can be achieved with TSZ duplex coatings. There are examples of 50-year old bridges with duplex coatings in good condition. Even in very corrosive environments, more than 40-year old coatings are still in good condition. While there are a few bridges in this study where the coating failed after only about 20 years, the typical coating failures are due to application errors, low paint film thickness and saponification of the paint. Modern bridge designs and improved coating systems are assumed to increase the duplex coating lifetime on bridges even further.
\end{abstract}

Keywords: thermal spray zinc; duplex coatings; coating lifetime; coating maintenance

\section{Introduction}

Road bridges are typically designed with a lifetime of 100 years. However, lifetime extensions are normal and there are many bridges that are older than 100 years. Bridges are most likely to be replaced or decommissioned due to increased traffic capacity or the closing of the road than for exceeding the design lifetime. With such long lifetimes, the maintenance of the protective coating is a major contributor to the operational expenses. Hence, coating systems with very long durability are of great interest. Multi-layer paint coating systems are specified in many countries, but such coating systems have limited lifetime, especially in corrosive environments. According to the ISO 12944-1 coating selection standard, a very long lifetime is defined as more than 25 years [1]. In a 100 years construction life perspective (or more than 100 years), 25 years is relatively short and implies that the coating must be maintained several times.

In order to increase the coating lifetime and reduce the coating maintenance costs, The Norwegian Public Roads Administration (NPRA) introduced thermally sprayed zinc (TSZ) duplex coatings for coastal steel bridges in 1965 and for all bridges in 1977, replacing red lead coatings. Klinge published a study of the TSZ duplex coating on the Rombak Bridge in Norway, documenting almost 40-year coating lifetimes $[2,3]$. The bridge was coated in the field with a duplex coating consisting of a pure zinc TSZ coating of $100 \mu \mathrm{m}$ and two layers of alkyd paint at $100 \mu \mathrm{m}$ each. The bridge was opened to traffic in 1965 and for various reasons left partly uncoated until 1970, when the duplex coating was 
applied. The bridge is a $750 \mathrm{~m}$ long suspension bridge with a bolted truss work under the bridgeway. The large numbers of overlapping joints in the truss work are typical corrosion traps, but the duplex coating even protected these from corrosion. In 2012, preventive coating maintenance was performed by washing and the application of a new topcoat due to the partial flaking of the old topcoat.

There is a long history of corrosion protection of steel bridges with TSZ coatings. The Ridge Avenue Bridge in Philadelphia was metalized with zinc already in 1938 [4]. In the UK, the Forth Road Bridge was installed with zinc metalized and painted steel in 1964, which was the largest metalized steel bridge at the time [5]. The coating performed very well in contrast to the parallel Forth Railway Bridge that was painted, probably with red lead. The experiences with the Forth Road Bridge were important when the NPRA started to specify TSZ duplex coatings in 1965. TSZ duplex coatings have later been extensively used in the Scandinavian countries, UK, France and, to some extent, in the USA and Canada. However, no extensive review of their performance has been published to our knowledge.

Duplex coatings consist of a metal coating, typically hot-dip galvanizing, electroplated zinc or TSZ, painted with a protective organic coating. TSZ with a sealer is usually not regarded as a duplex coating. Duplex coatings are now very common across many industry sectors. For example, in the automotive industry, duplex coatings are the norm for the manufacturing of about 50 million car bodies per year. TSZ duplex coatings for steel structures were already documented to perform well in the 19-year field test by the American Welding Society that was terminated in 1974 [6]. In his book from 1994, van Eijnsbergen published a comprehensive study of duplex coatings consisting of hot-dip galvanized steel and paint [7]. Based on his findings, he claimed that the durability of a duplex coating is longer than the sum of the durability of the metallic and the paint coatings:

$$
D_{\text {duplex }}=K \cdot\left(D_{\text {zinc }}+D_{\text {paint }}\right)
$$

where $D$ is the durability or lifetime of the coats and $K$ is a synergy factor, ranging from 1.5 in aggressive climates to 2.3 in less aggressive climates.

The objective of the present work has been to investigate the performance of zinc duplex coatings on 61 steel bridges in Norway as a function of corrosivity on site and the type of paint coating applied. Corrosivity was measured on four coastal bridges and one inland bridge in order to help estimate corrosivity on all the bridges. Typical coating failures and their causes are also discussed.

\section{Materials and Methods}

\subsection{Corrosivity}

Corrosivity was measured as material loss on steel panels according to ISO 9226 [8] on five road bridges, described in Table 1. The bridges were selected based on climatic conditions, height and availability for the deployment of samples. Gjemnessund and Sotra (43 and 14) are part of the coating condition study, while Nessundet, Tjeldsund and Hardanger are not because they have other coatings than investigated in this study. Annual temperature and precipitation averages and sailing clearance are given for each bridge in the table. Wind strength and direction will also affect corrosivity, but such data are not available and have not been measured in this study. 


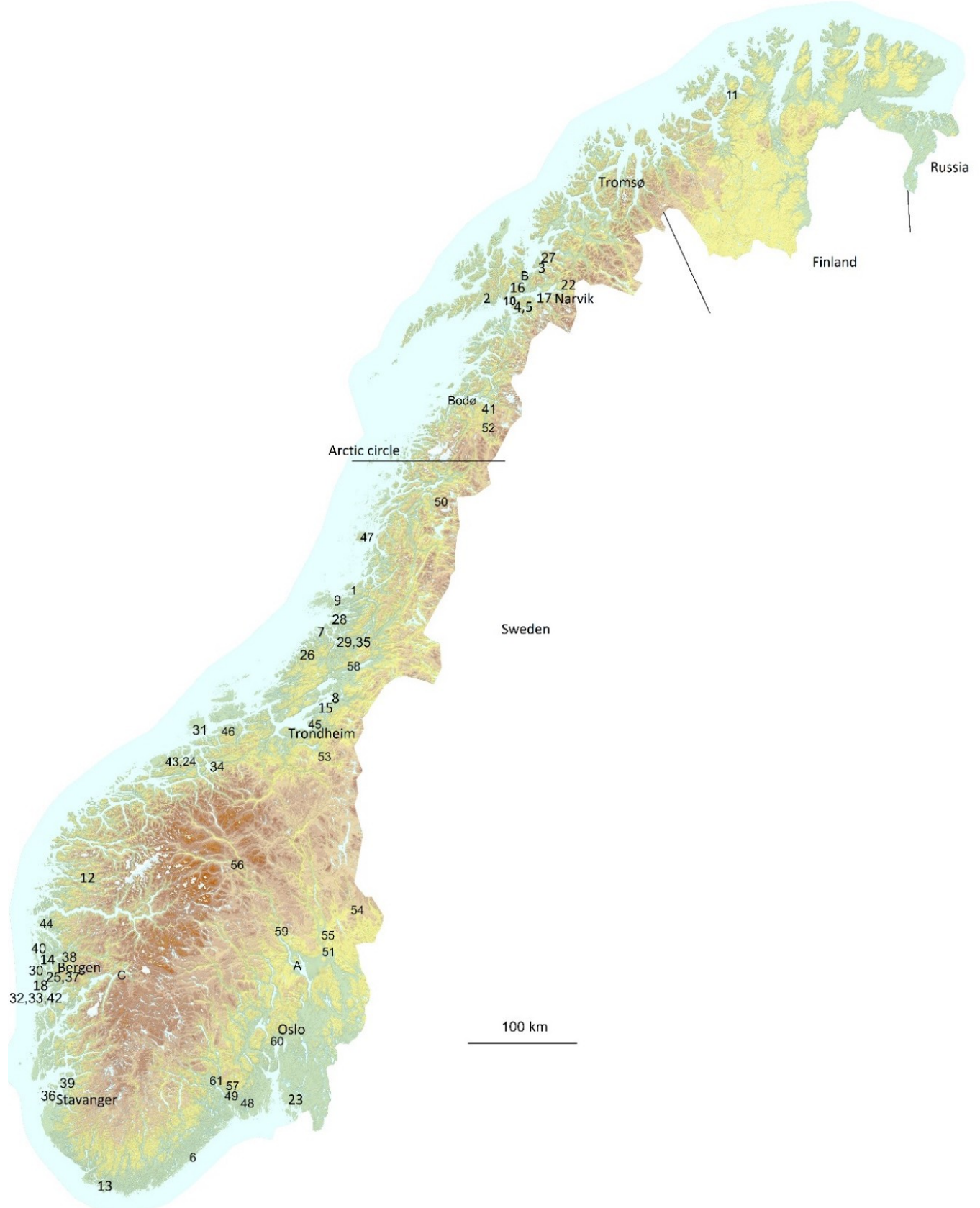

Figure 1. A map of Norway showing the location of the 61 bridges studied. Corrosivity was measured on bridges A, B, C, 14 and 43 .

Panels of cold rolled mild steel, $150 \mathrm{~mm} \times 100 \mathrm{~mm} \times 2 \mathrm{~mm}$ in dimensions, were exposed for one year. Corrosivity was measured at the level of the bridgeway on all the bridges. For Gjemnessund, Sotra and Hardanger, corrosivity was also measured on one tower at various heights between 5 and $70 \mathrm{~m}$ above sea level. After retrieval, the samples were cleaned in a solution of $500 \mathrm{~mL} 37 \% \mathrm{HCl}$ and $3.5 \mathrm{~g}$ hexamethylene-tetraamine diluted to $1000 \mathrm{~mL}$. The samples were kept in the solution for $10 \mathrm{~min}$ at room temperature. The corrosivity at the various sites was evaluated according to weight loss and labeled with a corrosion category according to ISO 12944-2 [9]. A corrosion depth of 1.3-25 $\mu \mathrm{m} / \mathrm{y}$ is category C2, $25-50 \mu \mathrm{m} / \mathrm{y}$ is C3, $50-80 \mu \mathrm{m} / \mathrm{y}$ is C4 and $80-200 \mu \mathrm{m} / \mathrm{y}$ is C5. Corrosion in the range $200-700 \mu \mathrm{m} / \mathrm{y}$ is category $\mathrm{CX}$, but such a high corrosivity was not measured in this study. Each corrosivity measurement was assessed from three replicate samples. 
The results from the corrosivity measurements were used to estimate corrosivity on all the 61 bridges in the study.

Table 1. The description of the bridges where corrosivity was measured. The location of the bridges is shown in Figure 1, labeled A, B, 43, 14 and C as given in the table.

\begin{tabular}{|c|c|c|c|c|}
\hline \multirow{2}{*}{ Bridge } & \multicolumn{3}{|c|}{ Climatic Conditions } & \multirow{2}{*}{$\begin{array}{l}\text { Sailing Clearance } \\
\text { (m) }\end{array}$} \\
\hline & Geography & $\begin{array}{l}\text { Temperature } \\
\text { Avg. }\left({ }^{\circ} \mathrm{C}\right)\end{array}$ & $\begin{array}{c}\text { Precipitation } \\
\text { Avg. (mm/year) }\end{array}$ & \\
\hline Nessundet (A) & Inland lake & 3 & 700 & 10 \\
\hline Tjeldsund (B) & Shielded coast & 3 & 1000 & 41 \\
\hline Gjemnessund (43) & Shielded coast & 7 & 1300 & 43 \\
\hline Sotra (14) & Exposed coast & 8 & 1900 & 50 \\
\hline Hardanger (C) & Shielded fjord & 6 & 1100 & 55 \\
\hline
\end{tabular}

\subsection{Bridges and Coatings}

Steel bridges longer than $100 \mathrm{~m}$ built between 1967 and 1995 were included in the study, 61 bridges in total. For C4 and C5 environments, shorter steel bridges were included to increase the number of bridges in these categories of corrosivity. The duplex coatings were specified from 1965, but assuming that it took some time to implement, only bridges from 1967 are included in this study. Bridges built after 1995 were not included due to the insufficient exposure time so far. The location of the 61 bridges is shown in Figure 1. For each bridge, corrosivity was estimated based on the corrosivity measurements on the five bridges described in Table 1. The estimates were based on the geographical location and sailing clearance. Average daily traffic was not assumed to affect the corrosivity significantly since the coated steel construction is located under the bridgeway on all the bridges in the study.

Two coating specifications were used in this period, as shown in Table 2. The only difference between the two specifications is that the zinc chromate in the two first alkyd coats was replaced with zinc phosphate in 1977.

Table 2. The coating specifications between 1965 and 1995.

\begin{tabular}{ccccc}
\hline Coat No. & \multicolumn{2}{c}{1965} & \multicolumn{2}{c}{1977} \\
\hline 1 & TSZ, pure Zn & $100 \mu \mathrm{m}$ & TSZ, pure Zn & $100 \mu \mathrm{m}$ \\
2 & Phosphoric acid wash primer & - & Phosphoric acid wash primer & - \\
3 & Alkyd with zinc chromate & $50 \mu \mathrm{m}$ & Alkyd with zinc phosphate & $50 \mu \mathrm{m}$ \\
4 & Alkyd with zinc chromate & $50 \mu \mathrm{m}$ & Alkyd with zinc phosphate & $50 \mu \mathrm{m}$ \\
5 & Alkyd & $50 \mu \mathrm{m}$ & Alkyd & $50 \mu \mathrm{m}$ \\
6 & Alkyd & $50 \mu \mathrm{m}$ & Alkyd & $50 \mu \mathrm{m}$ \\
\hline
\end{tabular}

\subsection{Coating Performance Data}

Coating condition has been assessed based on pictures from routine bridge inspections performed by NPRA personnel. A thorough coating inspection is performed every 5 years and the results are documented in the NPRA bridge management database. The database also contains information about coating maintenance. In addition, information about the extent and scope of maintenance has been collected from the NPRA personnel responsible for the specific maintenance operations. The coating condition on the various bridges have been assessed according to four categories defined for this study:

- Good: The paint coating is in good condition and little or no degradation can be seen;

- Fair: There is some paint degradation, and zinc corrosion products (white) can be found locally;

- Poor: The steel has started to corrode and red rust is found;

- Repaired: Coating maintenance has been performed; in most cases, patch repair with a full topcoat. 
The coating condition can vary across steel structures and typically overlapping joints, edges, welds and bolts are attacked by corrosion before the flat surfaces. Older truss construction bridges have more of these corrosion traps, while on modern box beam bridges these are, to a large extent, avoided. This has not been considered in the assessment. However, various coating application errors were found, which will be discussed.

\subsection{Coating Performance Indicator}

To enable a quantitative comparison of coating performance on the various bridges, a coating performance indicator (CPI) has been defined for this study:

$$
C P I=L+L \cdot \frac{S}{C}
$$

where $L$ is the coating lifetime for a repaired coating or present coating age for not repaired coatings, $C$ is the corrosivity category number (category 2-5) and $S$ is the assessment of condition described above, but numerical. The coating condition has been assessed as either good, fair, poor or repaired, which have been given the values 3, 2, 1 and 0 respectively. For repaired coatings, CPI will then be the coating lifetime. For not repaired coatings, the CPI will be the current age of the coating, with an additional expected life proportional to current age and condition, and inversely proportional to corrosivity. Though CPI may be regarded as an expected lifetime of not repaired coatings, such a claim cannot be made without further investigation into coating performance and maintenance, which is beyond the scope of this work. Here, the CPI is only used for estimating an indicator for coating performance to enable comparison.

\section{Results}

\subsection{Corrosivity}

Corrosivity at the level of the bridgeway on the five bridges is shown in Table 3. Hardanger bridge and Gjemnessund bridge are modern box beam bridges, while the others are older truss constructions. Nessundet bridge is an arch bridge, while the rest are suspension bridges. The samples were placed at different locations on the bridges, as shown in the table.

Table 3. The description of the bridges where corrosivity was measured and the corrosivity found at the level of the bridgeway.

\begin{tabular}{|c|c|c|c|c|c|c|}
\hline \multirow{2}{*}{$\begin{array}{c}\text { Bridge. } \\
\text { Measurement Site } \\
\text { Nessundet (A) }\end{array}$} & \multicolumn{3}{|c|}{ Climatic Conditions } & \multirow{2}{*}{$\begin{array}{l}\text { Sailing } \\
\text { Clearance } \\
\text { (m) }\end{array}$} & \multirow{2}{*}{\multicolumn{2}{|c|}{$\begin{array}{c}\text { Corrosivity } \\
\mu \mathrm{m} / \text { year Category }\end{array}$}} \\
\hline & Geography & $\begin{array}{c}\text { Temp. } \\
\text { Avg. }\left({ }^{\circ} \mathrm{C}\right)\end{array}$ & $\begin{array}{l}\text { Precipitation } \\
\text { Avg. }(\mathrm{mm} / \mathrm{y})\end{array}$ & & & \\
\hline $\begin{array}{c}\text { Nessundet (A) } \\
\text { Truss, west side } \\
\text { Truss, middle } \\
\text { Truss, east side }\end{array}$ & Inland lake & 3 & 700 & 10 & $\begin{array}{c}26 \\
6 \\
13\end{array}$ & $\begin{array}{l}\text { C3 } \\
\text { C2 } \\
\text { C2 }\end{array}$ \\
\hline $\begin{array}{l}\text { Tjeldsund (B) } \\
\text { Truss, south side } \\
\text { Truss, middle } \\
\text { Truss, north side }\end{array}$ & $\begin{array}{l}\text { Shielded } \\
\text { coast }\end{array}$ & 3 & 1000 & 41 & $\begin{array}{l}12 \\
13 \\
18\end{array}$ & $\begin{array}{l}\mathrm{C} 2 \\
\mathrm{C} 2 \\
\mathrm{C} 2\end{array}$ \\
\hline $\begin{array}{l}\text { Gjemnessund (43) } \\
\text { Pylon, west side } \\
\text { Bridgeway fence } \\
\text { Under bridgeway }\end{array}$ & $\begin{array}{l}\text { Shielded } \\
\text { coast }\end{array}$ & 7 & 1300 & 43 & $\begin{array}{l}11 \\
28 \\
48\end{array}$ & $\begin{array}{l}\mathrm{C} 2 \\
\mathrm{C} 3 \\
\mathrm{C} 3\end{array}$ \\
\hline $\begin{array}{c}\text { Sotra (14) } \\
\text { Pylon, west side }\end{array}$ & $\begin{array}{l}\text { Exposed } \\
\text { coast }\end{array}$ & 8 & 1900 & 50 & 27 & $\mathrm{C} 3$ \\
\hline $\begin{array}{l}\text { Hardanger }(\mathrm{C}) \\
\text { Pylon, west side }\end{array}$ & $\begin{array}{l}\text { Shielded } \\
\text { fjord }\end{array}$ & 6 & 1100 & 55 & 9 & $\mathrm{C} 2$ \\
\hline
\end{tabular}


The relative standard deviation for the measurements was $4 \%$ on average and ranging between $2 \%$ and $6 \%$ for the individual sets of three parallels. All measurements were performed during the 12 months in 2016-2017. Hence, variations from year to year are not accounted for.

The dominant wind direction is from the west on all the bridges. The Gjemnessund and Tjeldsund bridges are located behind larger islands and, therefore, somewhat shielded. Hardanger bridge is located deep inside a fjord and even more shielded. Freshwater from rivers reduce the salinity in the fjord to $3.1 \%$ at the bridge location, compared to $3.5 \%$ in the open sea, but this difference is assumed to be insignificant. Sotra bridge is quite exposed. Nessundet bridge is also somewhat exposed but crossing a strait in an inland lake where the only salt exposure is from winter deicing salt.

Annual precipitation varies significantly between the locations of the five bridges. The precipitation may have two opposite effects on corrosivity. Primarily, increasing precipitation will increase the time of wetness on the steel and thereby increase corrosion. However, in marine environments, precipitation may also decrease corrosion by washing off salt deposits. This effect is typically found under the bridgeway, where salt accumulates but never or rarely is washed away by rain [10]. Hence, in an inland environment, corrosivity will normally increase with annual precipitation, while in a coastal environment, the effect of precipitation may vary from place to place on the construction.

As Table 3 shows, the corrosivities measured at the level of the bridgeway are all within categories $\mathrm{C} 2$ and $\mathrm{C} 3$. On Nessundet bridge, the west side is more corrosive, probably because western winds are dominating. Under the bridgeway, the samples were shielded from rain, which resulted in a much lower corrosion rate than on the sides. Tjeldsund bridge is going east-west, so the difference between the directions are smaller, but the north side is slightly more exposed. On Gjemnessund, the corrosivity was highest under the bridgeway, where the samples were mounted on a vortex shedding blade. This is probably explained by the deposition of sea salt and shielding from rain that would wash the salt off the surface. The sailing clearance is $43 \mathrm{~m}$, but salt deposits are nevertheless found under the bridgeway. In general, coastal bridges are more susceptible to coating degradation and corrosion on the underside of the bridgeway due to this effect. On Sotra bridge, C3 corrosivity was found on the pylon at the level of the bridgeway. No measurements were performed on the bridgeway, which may have shown higher corrosivity, as found on Gjemnessund. Hardanger bridge, which is the most shielded of the five bridges showed low corrosivity. As for Gjemnessund, the corrosivity may have been somewhat higher on the bridgeway, but due to the high sailing clearance and wind shielding, the corrosivity is assumed to be low even here. Figure 2 shows corrosivity as a function of the height along one pylon on three of the bridges, measured from $5 \mathrm{~m}$ above the sea level. On Gjemnessund and Hardanger, the corrosivity was generally low all the way. For both bridges, this was somewhat surprising since the pylons are located near the sea. Airflow patterns around the massive concrete pylons may partly explain the difference, but the lower annual precipitation at these two sites may also have contributed, decreasing the time of wetness on the samples. For the Sotra bridge, it is interesting to see how the corrosivity decreases as a function of height. Up to about $12 \mathrm{~m}$, the corrosivity was category C5. Further up the corrosivity gradually decreased and reached almost category $\mathrm{C} 2$ from $45 \mathrm{~m}$.

From the corrosivity measurements, it is evident that the height above sea level has a large influence on corrosivity. Annual precipitation also seems to be an important parameter. Wind conditions are expected to contribute, but wind measurements on the investigated bridges have not been performed and cannot be discussed in this study. 


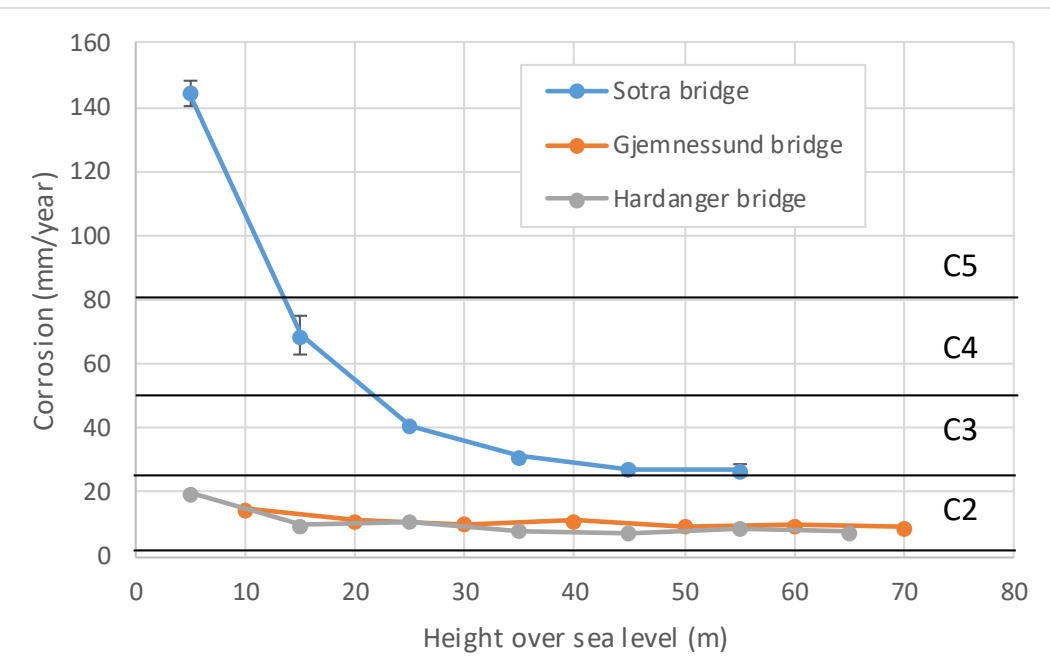

Figure 2. Corrosivity on three bridges as a function of height over sea level.

\subsection{Coating Lifetimes}

Tables 4 and 5 show the lifetime of duplex coatings on 23 steel bridges built between 1967 and 1977 and 38 bridges built between 1978 and 1995, respectively, 61 bridges in total. As shown in Table 2, the coating specification was changed during 1977 and the zinc chromate in the two first paint coats was replaced with zinc phosphate. Corrosivity is estimated for each bridge based on the geographical location and sailing clearance, relative to the five bridges where corrosivity was measured. Sailing clearance is given for all the coastal bridges. All the inland bridges are assumed to be in C2 environments. Winter salting of roads is assumed not to affect the corrosivity since the load bearing steel construction is located under the bridgeway for all the bridges in this study. There are few bridges in C2 environments in Table 4 since duplex coatings were not specified for inland bridges before 1977.

Table 4. The coating lifetime on coastal bridges built between 1967 and 1977. CPI is the coating performance indicator.

\begin{tabular}{|c|c|c|c|c|c|c|c|c|}
\hline & Name & $\begin{array}{l}\text { Corrosiv. } \\
\text { (C) }\end{array}$ & Built & $\begin{array}{c}\text { Clearance } \\
\text { (m) }\end{array}$ & $\begin{array}{c}\text { Condition } \\
\text { (S) }\end{array}$ & Maintenance & $\begin{array}{c}\text { Lifetime } \\
\text { (years) }\end{array}$ & CPI \\
\hline 1 & Madsøybrua & \multirow{2}{*}{ C5 } & 1975 & 6 & Repaired & 2000 & 25 & 25 \\
\hline 2 & Erikstadstrøm & & 1975 & 3 & Repaired & 2017 & 42 & 42 \\
\hline 3 & Grov & \multirow{9}{*}{$\mathrm{C} 4$} & 1968 & 7 & Repaired & 1996 & 28 & 28 \\
\hline 4 & Kjerringstraum & & 1969 & 15 & Repaired & 1998 & 29 & 29 \\
\hline 5 & Sørstraumen & & 1969 & 3 & Repaired & 1998 & 29 & 29 \\
\hline 6 & Strømsund & & 1970 & 4 & Repaired & 2017 & 47 & 47 \\
\hline 7 & Stamnes & & 1970 & 6 & Repaired & 2006 & 36 & 36 \\
\hline 8 & Verdal & & 1972 & 2 & Repaired & 1995 & 23 & 23 \\
\hline 9 & Kvalpsundet & & 1974 & 10 & Repaired & 1995 & 21 & 21 \\
\hline 10 & Slottvikstraumen & & 1974 & 6 & Fair & - & $>45$ & 68 \\
\hline 11 & Kvalsundbrua & & 1977 & 26 & Repaired & 2001 & 24 & 24 \\
\hline 12 & Naustdal Bru & \multirow{10}{*}{$\mathrm{C} 3$} & 1970 & 2 & Good & - & $>49$ & 90 \\
\hline 13 & Revøysund & & 1971 & 20 & Good & - & $>48$ & 96 \\
\hline 14 & Sotrabrua & & 1971 & 50 & Repaired & 2011 & 40 & 40 \\
\hline 15 & Sundbrua & & 1971 & 3 & Good & - & $>48$ & 96 \\
\hline 16 & Kjærfjorden & & 1972 & 5 & Repaired & 2010 & 38 & 38 \\
\hline 17 & Skjomen & & 1972 & 35 & Repaired & 2000 & 28 & 28 \\
\hline 18 & Tofterøy & & 1975 & 20 & Repaired & 2011 & 36 & 36 \\
\hline 19 & Kjellingstraumen & & 1975 & 29 & Good & - & $>44$ & 88 \\
\hline 20 & Randøy & & 1976 & 24 & Fair & - & $>43$ & 72 \\
\hline 21 & Lokkarbrua & & 1977 & 30 & Repaired & 2005 & 28 & 28 \\
\hline 22 & Rombaksbrua & \multirow{2}{*}{$\mathrm{C} 2$} & 1970 & 40 & Repaired & 2011 & 41 & 82 \\
\hline 23 & Rolvsøysund & & 1970 & 5 & Good & - & 49 & 123 \\
\hline
\end{tabular}


Table 5. The coating lifetime on bridges built between 1978 and 1995. CPI is coating performance indicator.

\begin{tabular}{|c|c|c|c|c|c|c|c|c|}
\hline & Name & $\begin{array}{l}\text { Corrosiv. } \\
\text { (C) }\end{array}$ & Built & $\begin{array}{c}\text { Clearance } \\
\text { (m) }\end{array}$ & $\begin{array}{l}\text { Condition } \\
\text { (S) }\end{array}$ & Maintenance & $\begin{array}{l}\text { Lifetime } \\
\text { (years) }\end{array}$ & CPI \\
\hline 24 & Bergsøysundbrua & \multirow{2}{*}{$\mathrm{C} 5$} & 1992 & 5 & Repaired & 2011 & 19 & 19 \\
\hline 25 & Nordhordlandsbrua & & 1994 & 5 & Repaired & 2017 & 23 & 23 \\
\hline 26 & Store Holmsund & \multirow{9}{*}{ C4 } & 1978 & 4 & Repaired & 2007 & 29 & 29 \\
\hline 27 & Åndervåg & & 1980 & 3 & Repaired & 2001 & 21 & 21 \\
\hline 28 & Nærøysund & & 1981 & 41 & Repaired & 2011 & 30 & 30 \\
\hline 29 & Ytterbystrømmen & & 1982 & 4 & Good & - & $>37$ & 65 \\
\hline 30 & Torvsundet & & 1984 & 5 & Fair & - & $>35$ & 53 \\
\hline 31 & Kulisvabrua & & 1988 & 16 & Fair & - & $>31$ & 47 \\
\hline 32 & Klubbasund & & 1989 & 20 & Fair & - & $>30$ & 45 \\
\hline 33 & Djupasund & & 1990 & 20 & Poor & - & $>29$ & 36 \\
\hline 34 & Bøfjordbrua & & 1992 & 2 & Poor & - & $>27$ & 34 \\
\hline 35 & Høyknesbrua & \multirow{13}{*}{$\mathrm{C} 3$} & 1978 & 5 & Fair & - & $>41$ & 68 \\
\hline 36 & Stavanger Bybru & & 1978 & 26 & Poor & - & $>41$ & 55 \\
\hline 37 & Haglesundbrua & & 1982 & 50 & Fair & - & $>37$ & 62 \\
\hline 38 & Eikanger I & & 1987 & 5 & Good & - & $>32$ & 64 \\
\hline 39 & Helgøysund & & 1988 & 14 & Fair & - & $>31$ & 52 \\
\hline 40 & Bukkholmstraum & & 1988 & 16 & Fair & 2012 & 24 & 52 \\
\hline 41 & Botn Bru & & 1991 & 2 & Good & - & $>28$ & 56 \\
\hline 42 & Brandasund & & 1991 & 24 & Fair & - & $>28$ & 47 \\
\hline 43 & Gjemnessundbrua & & 1991 & 43 & Fair & - & $>28$ & 47 \\
\hline 44 & Mjåsund & & 1993 & 30 & Fair & - & $>26$ & 43 \\
\hline 45 & Sandfærhus & & 1995 & 5 & Fair & - & $>24$ & 40 \\
\hline 46 & Dromnessundbrua & & 1995 & 16 & Good & - & $>24$ & 48 \\
\hline 47 & Grimsøy Bru & & 1995 & 10 & Good & - & $>24$ & 48 \\
\hline 48 & Hvåra & \multirow{14}{*}{$\mathrm{C} 2$} & 1978 & - & Good & - & $>41$ & 103 \\
\hline 49 & Ulefossbrua & & 1978 & - & Fair & - & $>41$ & 82 \\
\hline 50 & Korgen Bru & & 1978 & - & Good & - & $>41$ & 103 \\
\hline 51 & Glåmbrua Elverum & & 1979 & - & Good & - & $>40$ & 100 \\
\hline 52 & Pothus & & 1979 & - & Good & - & $>40$ & 100 \\
\hline 53 & Moslett & & 1980 & - & Good & - & $>39$ & 98 \\
\hline 54 & Jordet bru & & 1981 & - & Good & - & $>38$ & 95 \\
\hline 55 & Åmot bru & & 1981 & - & Good & - & $>38$ & 95 \\
\hline 56 & Sundbru Ny & & 1981 & - & Good & - & $>38$ & 95 \\
\hline 57 & Akkerhaugen & & 1981 & - & Good & - & $>38$ & 95 \\
\hline 58 & Nødalsbrua & & 1982 & - & Good & - & $>37$ & 93 \\
\hline 59 & Lillehammer & & 1984 & - & Good & - & $>35$ & 88 \\
\hline 60 & Grinienga & & 1986 & - & Good & - & $>33$ & 83 \\
\hline 61 & Nautesund & & 1986 & - & Good & - & $>33$ & 83 \\
\hline
\end{tabular}

A graphical summary of the coating performance on the bridges in Table 4 is given in Figure 3a. Of the 23 bridges, 16 have received coating maintenance, i.e., about $70 \%$. Of these, eight are in C4 environments, five in $\mathrm{C} 3$ environments a one in a $\mathrm{C} 2$ environment. The repair of the $\mathrm{C} 2$ bridge was preventive maintenance due to topcoat flaking and not corrosion. Both the two bridges in the $\mathrm{C} 5$ environment have received maintenance. Of the remaining bridges, two are in a fair condition and five are in good condition.

The coating performance of bridges in Table 5 is shown graphically in Figure $3 b$ for the 38 bridges built between 1978 and 1995. Of the 38 bridges, only five have received coating maintenance so far, i.e., about $13 \%$. These five bridges are all exposed in C4 or C5 environments. Not surprising, the duplex coatings are performing very well in C2 environments. Contrary to Figure $3 a$, Figure $3 b$ does show a correlation between corrosivity and coating performance.

The performance of the coatings in the C 5 environment is similar for bridges coated with the 1965 specification and with the 1977 specification. The Madsøybrua and Erikstadstrøm bridges listed in Table 4 were repaired after 25 and 42 years, respectively. The Bergsøysundbrua and Nordhordlandsbrua bridges listed in Table 5 were repaired after only 19 and 23 years. A close inspection of the coatings reveals that application errors led to the failures on Bergsøysundbrua and Nordhordlandsbrua. Both bridges are floating bridges and may be regarded as mainly exposed in the marine splash zone. In the offshore industry, the corrosion rate in the marine splash zone is assumed to be $400 \mu \mathrm{m} / \mathrm{y}$, i.e., corrosivity category CX [9]. Hence, to classify these bridges as category C5 may be too low. 
The coatings were mainly degraded on the underside of the bridgeway, where marine salt deposits will never be washed off by rain. Hence, a concentrated and very aggressive brine is formed on the coating surface. For Bergsøysundbrua, the maintenance started too early. Even though the organic coating had partly failed, the zinc coating was still protecting the steel. For Nordhordlandsbrua, the degradation was more severe and the steel had started to corrode in some areas.

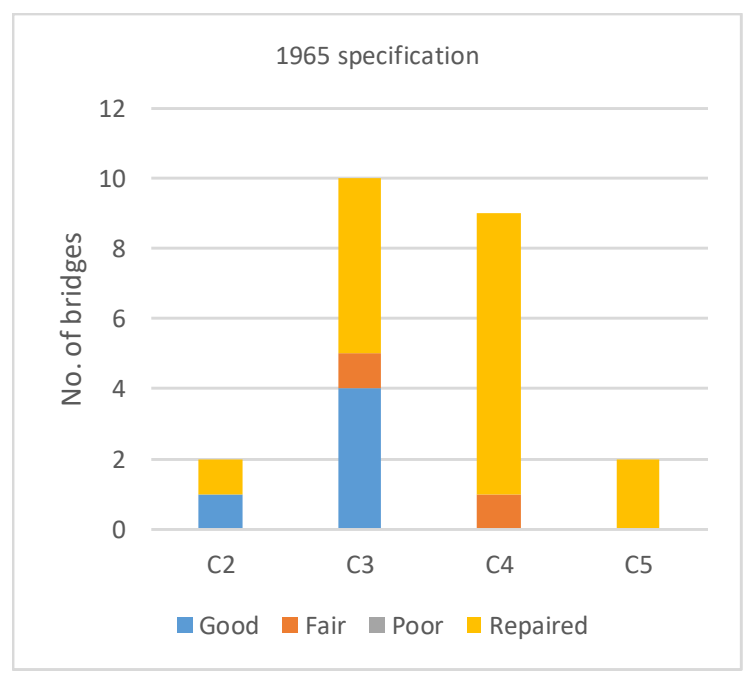

(a)

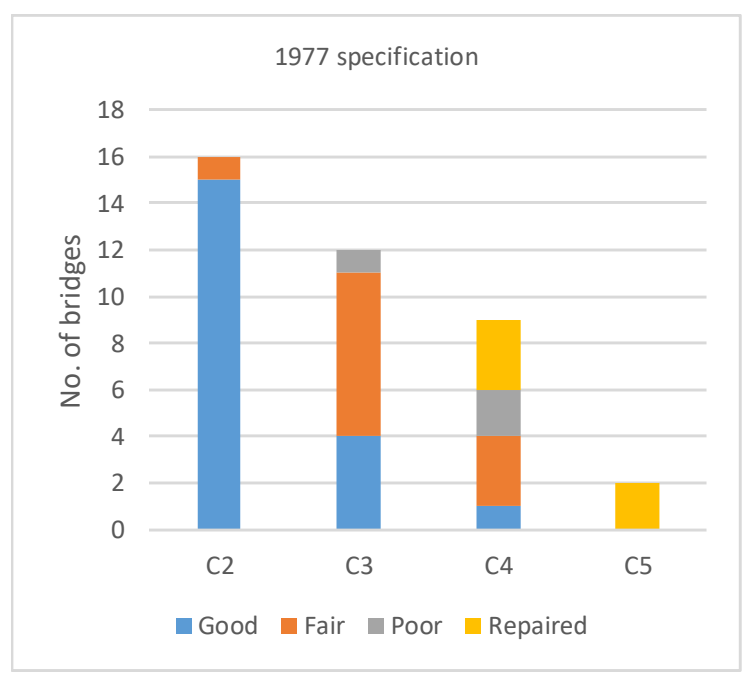

(b)

Figure 3. The summary of coating condition for the two specifications as a function of corrosivity: (a) 1965 specification; (b) 1977 specification.

\subsection{Coating Performance versus Corrosivity}

Figure $4 \mathrm{a}$ shows the average age and age span of the bridges in the study, illustrating the difference in exposure time for the two coating specifications. Since only 21 of the 61 bridges has received coating maintenance so far, the average coating lifetimes as defined by time to first major coating maintenance (ISO 12944-1 [11]) cannot be calculated. Only the result for the C5 exposures represents actual lifetime since all bridges have had coating maintenance. In order to enable a quantitative comparison of coating performance, the coating performance indicator (CPI) was defined, as described above. The average CPI as a function of corrosivity is shown in Figure $4 \mathrm{~b}$, while the CPI for each bridge is given in Tables 4 and 5 . The error bars show the standard deviation. Figure $4 \mathrm{~b}$ shows that the coating performance increases with decreasing corrosivity for both coating specifications, as expected. There are only two bridges in both the $\mathrm{C} 2$ and $\mathrm{C} 5$ environments for the 1965 specification though, which gives a rather weak statistical base for making conclusions. Additionally, the standard deviation is rather high for several of the categories, but the trend in the results is evident. 


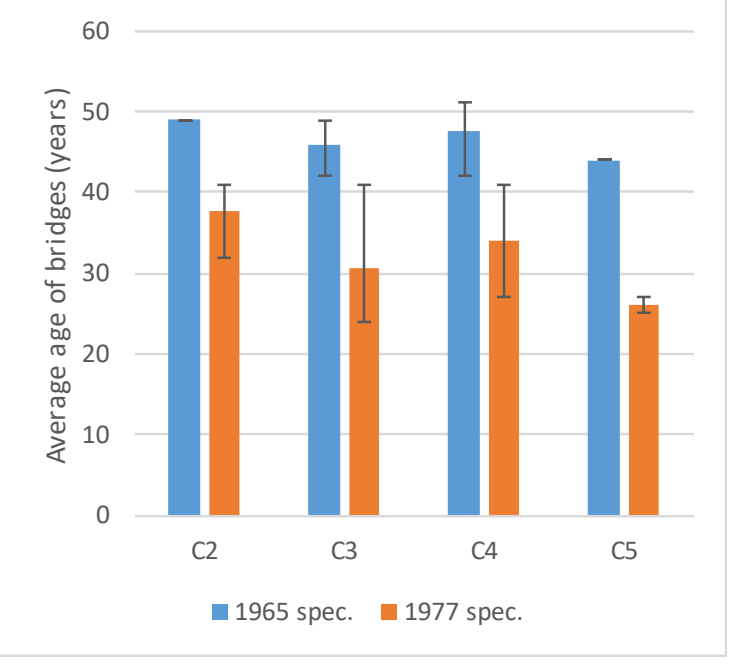

(a)

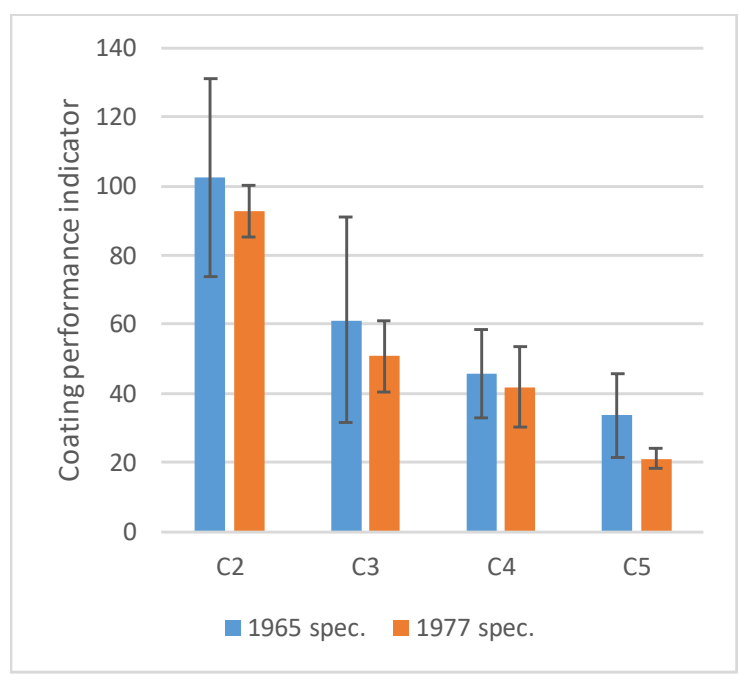

(b)

Figure 4. The coating age and performance: (a) Average age of the bridges. The bars show the highest and lowest age within each category of corrosivity; (b) Coating performance indicator as a function of corrosivity. The bars indicate standard deviation.

\subsection{Coating Failure Mechanisms}

Four different coating failure mechanisms have been identified in this study, of which two are specific to TSZ duplex coatings, and two are generally found in paint coatings. The most common failure mechanism was an insufficient barrier due to low paint film thickness. In many cases, this was found at steel edges, e.g., flanges on H-beams. This is typical for all paint coatings that are applied as a wet film. Due to surface tension, the paint will retract from sharp edges in order to reduce surface area, resulting in an inferior film thickness. Poor edge retention being a typical failure mode for paint has been subject to investigation, e.g., by Yun et al. [12].

Another reason for low film thickness that is specific to TSZ duplex coatings is the lack of an instrument that can measure paint film thickness over TSZ. The commonly used magnetic film thickness gauges will measure the total duplex film thickness, i.e., both TSZ and paint. The eddy current thickness gauges that will measure thickness over the first electrically conducting layer, i.e., the zinc coating, does not work well with TSZ due to its rough microstructure and porosity (see Figure 5). This makes large variations in conductivity and unstable measurements. The magnetic thickness gauge is, therefore, presently the only option. Ideally, each coating thickness should be measured as applied to ensure the coatings meet specifications.

The second failure mechanism is the formation of pinholes in the paint film [13]. When applying paint on TSZ, bubbles of trapped air and evaporating solvent are easily formed inside the film, probably due to the rough surface structure of the TSZ. As the bubbles grow, they attract paint from around and the wet film thickness grows locally. When the paint dries, the bubbles crack open, but if the opening is too narrow, it will not be filled by the subsequent coats. Thus, a pinhole is formed in the paint where the zinc will start to corrode at an early stage.

The third failure mechanism found was "spitting" during thermal spraying. If the arc spray gun is not properly adjusted, there will be incomplete melting of the zinc wire. These pieces of solid zinc will be sprayed along with the melted zinc but may protrude from the surface as tall peaks. When the paint is applied, the film thickness will be too low over these peaks and the paint will fail during exposure. A typical example is shown in Figure 6. 


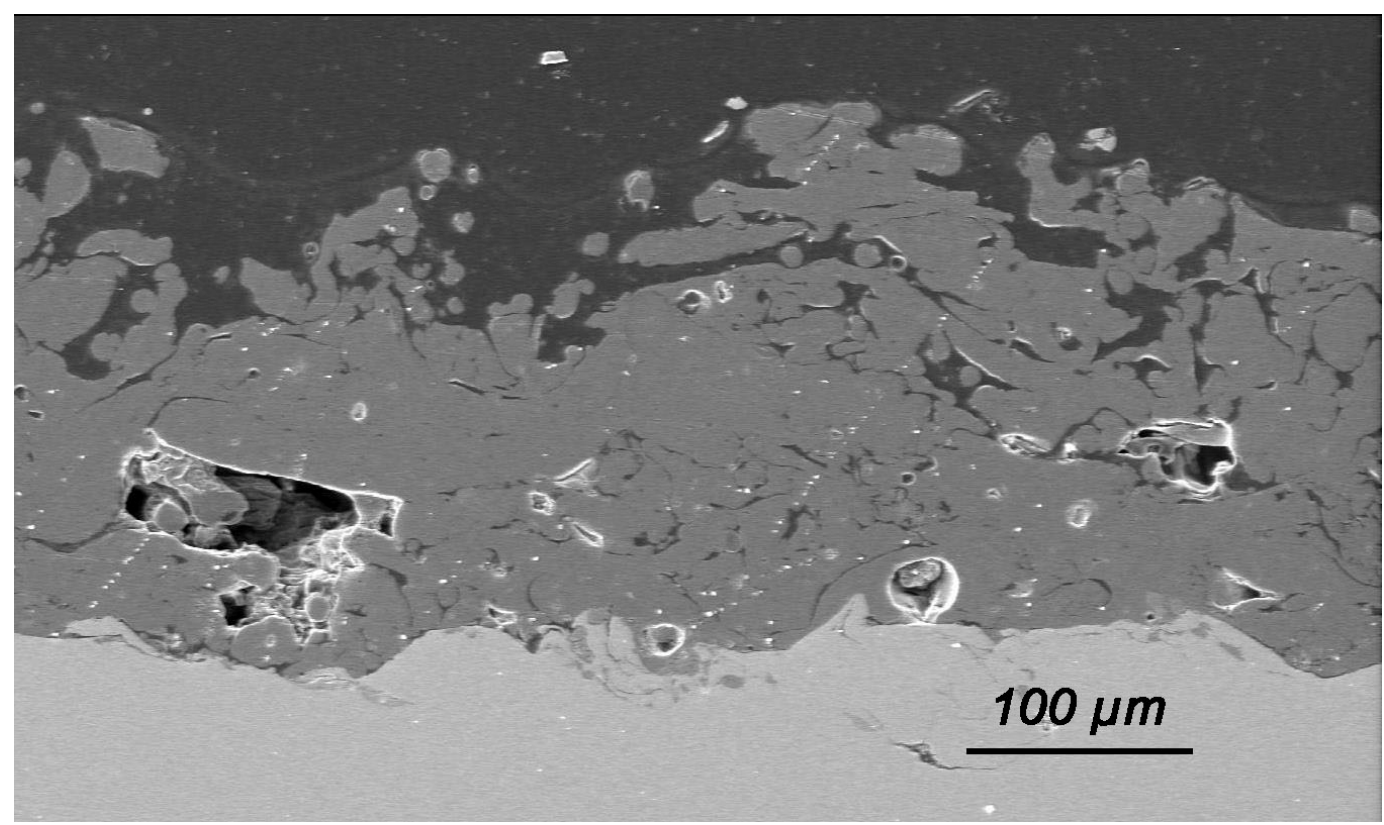

Figure 5. The cross-section of Thermal spray zinc (TSZ) coating. The very rough microstructure affects the conductivity of the coating, which results in a very large variation in paint film thickness measurements with Eddy current gauge.

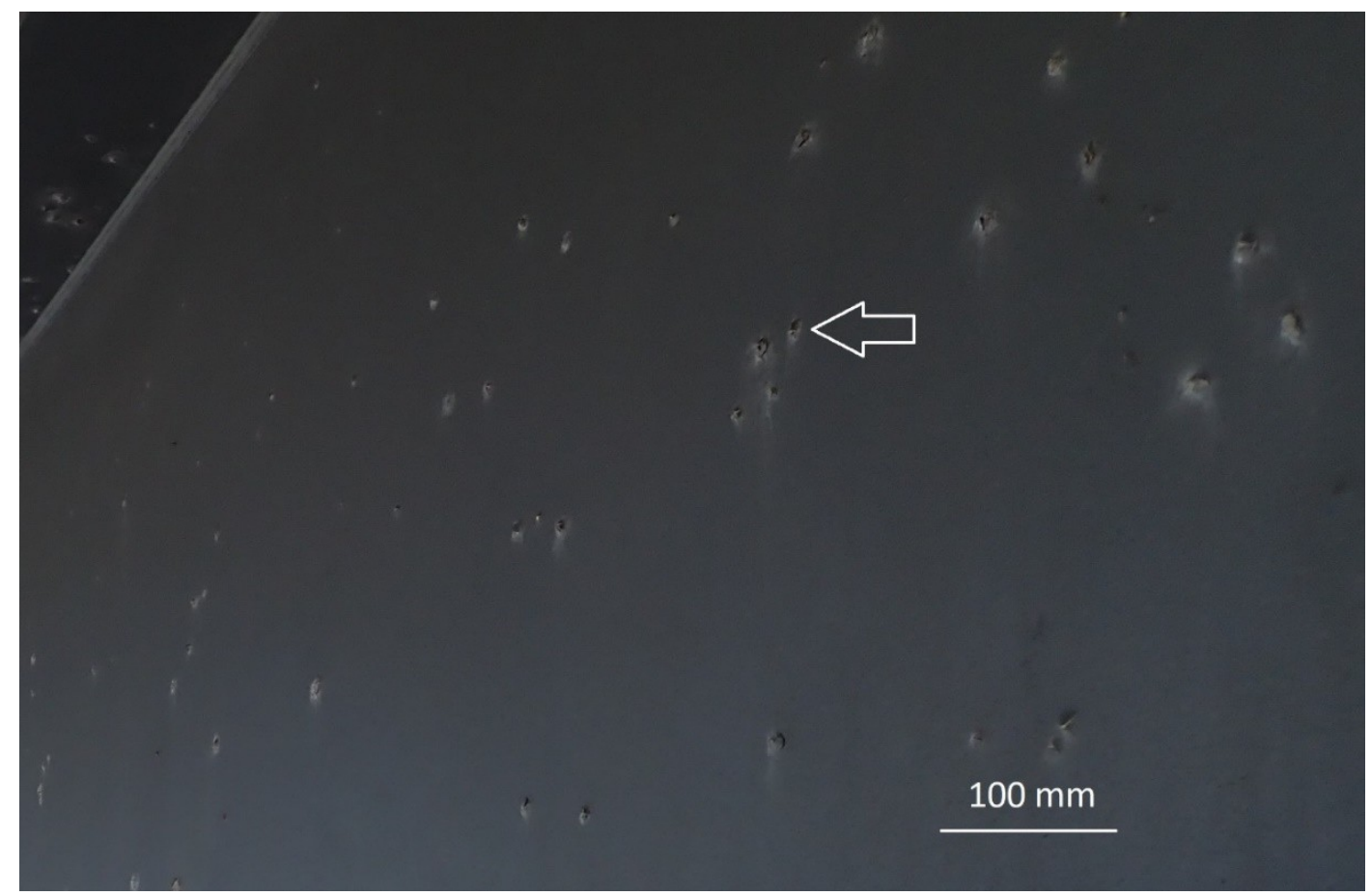

Figure 6. The corrosion of the TSZ due to "spitting" during thermal spraying. All the protrusions in the coating, one of them marked with an arrow, is due to spitting during thermal spraying. The paint film is too thin over the zinc protrusions and the zinc starts to corrode. Photo: NPRA.

The fourth failure mechanism is the hydrolysis of the alkyd paint in contact with concrete. The ester bonds in the alkyd binder are broken when exposed to an alkaline environment. This is also called saponification and is a well-known degradation mechanism for alkyds [14]. This was typically found on the upper flange of H-beams carrying a concrete bridgeway, see Figure 7. 


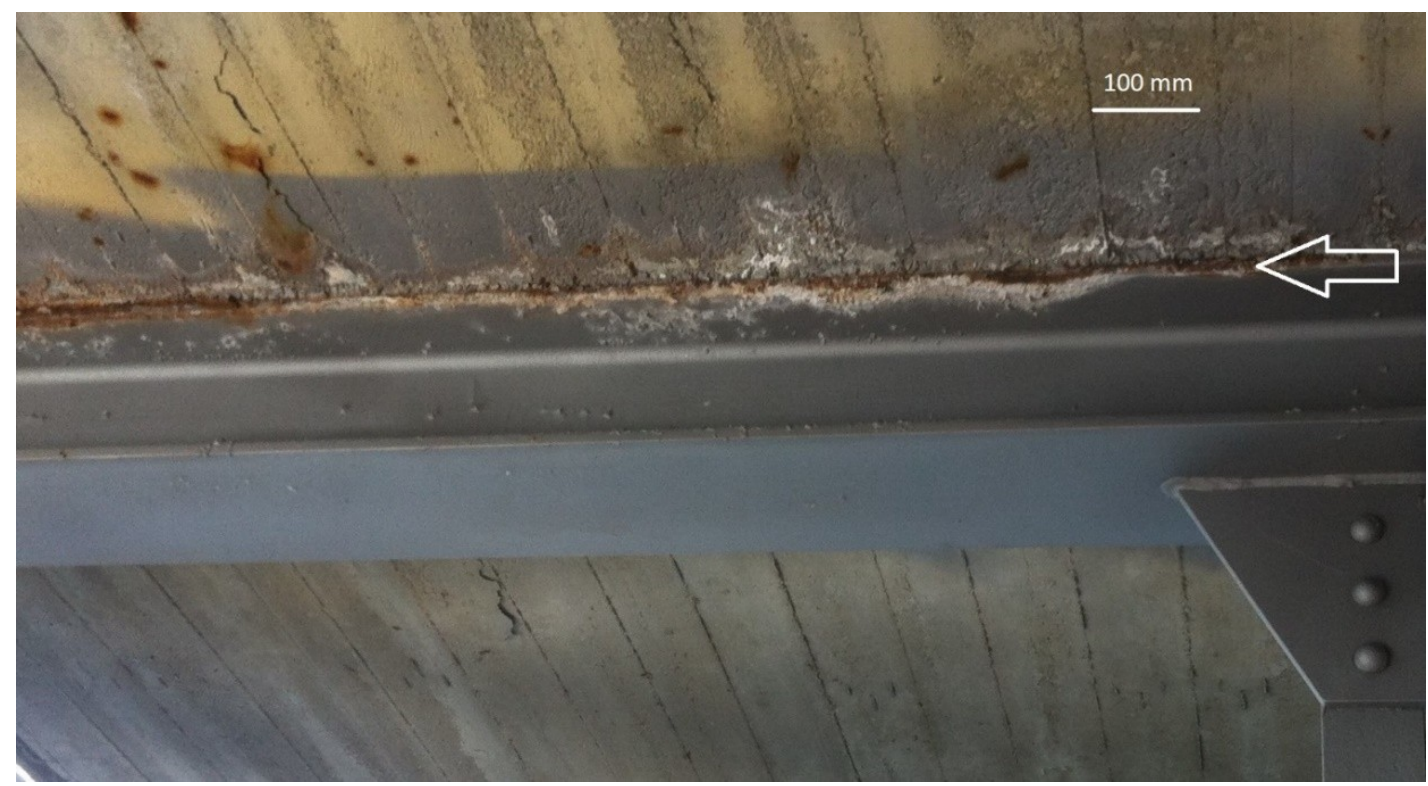

Figure 7. The saponification of alkyd paint where the painted H-beam is in contact with the concrete (marked with an arrow) and subsequent corrosion of zinc and steel.

\section{Discussion}

\subsection{TSZ Duplex Coating Failure Mechanisms}

The coating failure mechanisms that were identified have different origins. Pinholes and spitting are typical application errors with TSZ duplex coatings. When coating a large bridge, such errors are likely to appear occasionally. By adjusting the application parameters immediately to prevent further formation of such errors, and light grinding with sandpaper before application of the next coat, the quality of the coating will improve significantly. Mainly pinholes and spitting were responsible for the degradation at Bergsøysundbrua and large amounts of pinholes were also found at Nordhordlandsbrua. In the very corrosive C 5 environment, the TSZ started to corrode locally shortly after the bridge was built. The TSZ was protecting the steel, but the TSZ has a certain capacity for protection and when it is consumed, the steel starts to corrode.

Low film thickness results in coating failure due to the penetration of ions. Studies have shown that a protective coating should have a resistivity of more than $10^{9} \mathrm{Ohm} \cdot \mathrm{cm}^{2}$ [15]. The film thickness required to reach this resistivity depends on the generic type of coating. The thickness specification given by the coating supplier will normally provide the required barrier. Low film thickness over edges due to low edge retention is a general problem with paint. TSZ duplex coatings will give longer lifetimes than pure paint coating systems since the TSZ coat is not susceptible to this. The TSZ film thickness will be the same over sharp edges as on flat surfaces. However, if the paint film degrades early, the TSZ will start to corrode, and depending on the corrosivity, it will eventually be consumed. Grinding and stripe-coating of edges are routinely performed to reduce this problem, but it will not be eliminated. On modern box beam bridges, the amount of edges is significantly reduced, compared to a truss bridge.

Low paint film thickness on flat surfaces was one of the main degradation mechanisms on Nordhordlandsbrua. The zinc started to corrode under the paint after a few years due to a combination of low film thickness and formation of a very aggressive brine under the bridgeway, where rain never could wash deposited sea salt away. Inspections and control during painting seem to have been insufficient. This problem may be negligible with modern epoxy coatings. The old alkyd paints were applied in thin coats specified at $50 \mu \mathrm{m}$ each. High build epoxy mastic coatings typically must be applied in thicker coats in order to form a continuous film. Hence, the painter will see when enough paint has been applied, i.e., an inherent "smartness" in the paint. 
The saponification problem was found on most bridges where a concrete bridgeway was resting on a coated H-beam. This problem was eliminated when the NPRA paint specification was changed from alkyds to epoxies. Epoxies are very tolerant to the alkaline conditions in concrete.

\subsection{The Durability of TSZ Duplex Coatings}

Coating maintenance constitutes the main operational cost for most steel bridges. Given the long lifetime of bridges, coating durability is a key factor for reducing life cycle costs. The TSZ duplex coatings investigated in this study provide very long lifetimes and, for most bridges, significantly longer than 25 years, which is defined as a "very high" lifetime in ISO 12944-1. Since only about 70\% of the bridges with the 1965 coating specification and about 13\% of the bridges with the 1977 coating specification have been repaired, and many of the bridges still have coatings in good or fair condition, even longer lifetimes will be achieved. For the less corrosive environments at least, it is likely that duplex coatings may last for the lifetime of the bridge.

There are several sources of variation that complicate the comparison of coating performances. Most important is the sample size. As stated earlier, the study includes few bridges in C 5 environments, which constitute a weak statistical base for comparison. Geographical location plays a role. Bridges with the same sailing clearance may have different orientations or see different weather patterns leading to variable coating performance. Criteria for coating maintenance will affect the calculated performance indicator. Decisions about coating maintenance are made by different people and no firm criteria have been set by the NPRA. For example, the coating maintenance on Rombak bridge in 2011 was initiated as a preventive action. There was no corrosion on the bridge, but the topcoat had flaked off from parts of the bridge and the topcoat was renewed to prevent a more expensive maintenance operation in the future. The maintenance of the Nordhordland bridge, however, was initiated due to extensive coating degradation under the bridgeway and corrosion of the steel. In addition, non-technical factors affect the decision, like the available maintenance budget. Corrosion is a slow process and coating maintenance can often be postponed for many years without compromising the load carrying capacity of the bridge.

Both the 1965 and the 1977 coating specifications show a correlation between coating performance and corrosivity. The coatings have performed very well in mild conditions and failed earlier in corrosive conditions. Though the coating failures in C5 environments, at least partly, was due to coating application errors; this suggests that a stronger paint coating is required in corrosive environments. When the paint fails, the zinc coating will first act as a barrier, and later as a sacrificial anode when bare steel is exposed. Zinc is an active metal and even the $15 \%$ aluminum alloy that is used mainly today will have a certain corrosion rate. Hence, when the zinc is exposed, the remaining lifetime of the coating will be limited by its corrosion rate, which again is determined by the local corrosivity. The durability of a TSZ duplex coating in a corrosive environment is, therefore, very dependent on the performance of the paint coating.

\section{Conclusions}

Thermal spray zinc duplex coatings have provided long term corrosion protection to steel bridges in Norway. Considering the present coating age and condition, it is reasonable to assume that the duplex coating may last the entire 100-year bridge design life for many of the bridges in this investigation. For very corrosive environments, the two paint coating specifications appear to have been too weak.

Application quality has the strongest impact on coating life. Application errors like pinholes, spitting and low paint film thickness caused most coating failures found in this study. These errors decrease the protective properties of the paint film. The zinc coating provides active corrosion protection, but will have a definite lifetime, depending on the corrosivity. Hence, such application errors will reduce the coating lifetime more in corrosive environments than in mild environments. 
Some of the coating degradation mechanisms found in this study will be significantly reduced or eliminated with modern bridge designs and modern paint systems, which probably will increase TSZ duplex coating durability in the future. The most important improvements being

- Box beam bridge designs with fewer edges, reducing the edge retention problem

- Using epoxy coatings with high tolerance to alkaline environments

- Coatings with an inherent "smartness", that tell the painter when enough paint is applied

- Awareness of the spitting and pinhole problems so that adequate measures can be made during the application

Author Contributions: Conceptualization, O.Ø.K., C.D. and H.M.; Investigation, O.Ø.K.; Data curation, O.Ø.K., C.D. and H.M.; Writing—original draft preparation, O.Ø.K.; Writing—review and editing, M.G.; Funding acquisition, C.D., H.M. and M.G.

Funding: This research was funded by the Norwegian Public Roads Administration, contract number 2014059758, and the International Zinc Association.

Acknowledgments: Funding from the Norwegian Public Roads Administration and the International Zinc Association is gratefully acknowledged.

Conflicts of Interest: The International Zinc Association promotes the use of zinc worldwide, including for corrosion protection. However, they do not sell any products or services, and were not involved in the data collection or interpretation in this study. The NPRA is a governmental body and responsible for all public road bridges in Norway but has no commercial interests in coatings. They made their entire bridge administration database available to the project and put no limitations on the data selection. The decision to publish this study was made by O.Ø. Knudsen, SINTEF.

\section{References}

1. ISO 12944-5 Paints and Varnishes-Corrosion Protection of Steel Structures by Protective Paint Systems. Part 5: Protective Paint Systems; The International Organization for Standardization: Geneva, Switzerland, 2018.

2. Klinge, R. Protection of norwegian steel bridges against corrosion (Korrosionsschutz von Norwegischen Stahlbrücken). Stahlbau 1999, 68, 382-391. [CrossRef]

3. Klinge, R. Altered specifications for the protection of norwegian steel bridges and offshore structures against corrosion. Steel Constr. Des. Res. 2009, 2, 109-118. [CrossRef]

4. Porter, F.C. Zinc Handbook: Properties, Processing, and Use in Design; CRC Press: Boca Raton, FL, USA, 1991.

5. Perkins, R.A. Metallized Coatings for Corrosion Control of Naval Ship Structures and Components; National Materials Advisory Board: Washington, DC, USA, 1983; No. NMAB-409.

6. AWS. Corrosion Test of Flames-Sprayed Coated Steel. 19-Year Report; American Welding Society: Miami, FL, USA, 1974; No. C2.14-74.

7. Eijnsbergen, J.F.H.v. Duplex Systems. Hot-Dip Galvanizing Plus Painting; Elsevier Science: Amsterdam, The Netherlands, 1994; p. 222.

8. ISO 9226 Corrosion of Metals and Alloys_Corrosivity of Atmospheres-Determination of Corrosion Rate of Standard Specimens for the Evaluation of Corrosivity; The International Organization for Standardization: Geneva, Switzerland, 2012.

9. ISO 12944-2 Paints and Varnishes-Corrosion Protection of Steel Structures by Protective Paint Systems. Part 2: Classification of Environments; The International Organization for Standardization: Geneva, Switzerland, 2017.

10. Kreislova, K.; Geiplova, H. Evaluation of corrosion protection of steel bridges. Procedia Eng. 2012, 40, $229-234$. [CrossRef]

11. ISO 12944-1 Paints and Varnishes-Corrosion Protection of Steel Structures by Protective Paint Systems. Part 1: General Introduction; The International Organization for Standardization: Geneva, Switzerland, 2017.

12. Yun, J.T.; Kwon, T.K.; Kang, T.S.; Kim, K.L.; Kim, T.K.; Han, J.M. A critical study on edge retention of protective coatings for a ship hull. In Proceedings of the CORROSION 2005, Houston, TX, USA, 3-7 April 2005; National Association of Corrosion Engineers (NACE): Houston, TX, USA, 2005.

13. Hasselø, J.-A.; Djuve, G. Coating systems with long lifetime-paint on thermally sprayed zinc. In Proceedings of the CORROSION 2016, Vancouver, BC, Canada, 6-10 March 2016; National Association of Corrosion Engineers (NACE): Houston, TX, USA, 2016. 
14. Knudsen, O.Ø.; Forsgren, A. Corrosion Control through Organic Coatings; Taylor \& Francis: London, UK, 2017.

15. Bierwagen, G.P.; He, L.; Li, J.; Ellingson, L.; Tallman, D. Studies of a new accelerated evaluation method for coating corrosion resistance-Thermal cycling testing. Prog. Org. Coat. 2000, 39, 67-78. [CrossRef]

(C) 2019 by the authors. Licensee MDPI, Basel, Switzerland. This article is an open access article distributed under the terms and conditions of the Creative Commons Attribution (CC BY) license (http://creativecommons.org/licenses/by/4.0/). 